\title{
Strategi PT Pelabuhan Indonesia III (Persero) dalam Pengembangan Pelabuhan Benoa sebagai Cruise Turn Around Port
}

\author{
I Nyoman Gede Danendra Kenaka Yoga Iswara \\ Universitas Airlangga \\ e-mail: yogaiswr@gmail.com
}

\begin{abstract}
Sea transportation has an important role in economic growth in each country, including Indonesia. As a maritime country, sea transportation has a strategic role in improving people's welfare through the distribution of goods and passengers between islands. Nominally, goods are the major contributors to the revenues of PT Pelindo III (Persero). Goods compared, the passenger's segment only accounts for around $0.74 \%$ of total revenue. Nevertheless, PT Pelindo III (Persero) gives special remark to international passengers with the development of Benoa Port as a cruise turn around port. This is due to the high traffic of cruise ships or international passenger ships visiting the port over the past 5 years. Meanwhile, this cruise ship visit helped boost the velocity of money in the Bali region as well as creating a domino effect for the surrounding community. This research is a qualitative research and uses in-depth interviews with 6 informants. 4 people from the internal and 2 from customers' side. The research uses Porter's Five Forces in analyzing PT Pelindo III (Persero) as well as output in the form of an appropriate strategy proposal in the development of Benoa Port. The results of the study show that PT Pelindo III (Persero) needs to 1) Improve work culture, 2) Restructuring and regenerating human capital, 3) Cooperation and synergy of SOEs, 4) Improving service levels, 5) Optimizing facilities and 6) Setting reasonable tariffs.
\end{abstract}

Keywords: port, Benoa, strategy, marketing, cruise turn around port

\section{PENDAHULUAN}

\section{Latar Belakang Masalah}

Transportasi laut memiliki peranan penting dalam pertumbuhan ekonomi di setiap negara, tidak terkecuali Indonesia. Sebagai negara maritim, angkutan laut di Indonesia mempunyai peran strategis dalam meningkatkan kesejahteraan rakyatnya melalui distribusi barang antar-pulau (Purnomo, 2010). Adanya peningkatan perekonomian menurut data Badan Pusat Statistik Tahun 2016, membuktikan bahwasanya transportasi laut secara tidak langsung mendukung pertumbuhan ekonomi (Nugroho et al, 2017). Untuk itu diperlukan adanya pembangunan infrastruktur perhubungan laut, yang erat kaitannya dengan perbaikan lalu lintas barang dan penumpang. Mengingat wilayah Indonesia didominasi oleh kepulauan, transportasi laut memiliki peranan penting untuk meningkatkan konektivitas antarpulau di Indonesia yaitu sebagai alat mobilitas manusia dan barang. Dengan demikian, penyediaan prasarana dan sarana transportasi terus dituntut untuk meningkatkan efisiensi pelayanan (Purnamasari, 2018). Salah satu penyediaan prasaran dan sarana transportasi laut adalah dengan adanya pelabuhan.

Pelabuhan di Indonesia diklasifikasikan menjadi dua kelompok yaitu pelabuhan yang diusahakan dan pelabuhan yang tidak diusahakan, di mana kedua pelabuhan ini memiliki tujuan yang sama yaitu melayani kegiatan angkutan laut hanya saja fasilitas pada pelabuhan yang tidak diusahakan tidak selengkap pelabuhan yang diusahakan.

Pada tahun 2012, jumlah pelabuhan yang diusahakan ada sebanyak 111. Jumlah tersebut 
tidak bertambah hingga tahun 2015, dan mengalami penurunan dua tahun setelahnya yaitu menjadi 108 pelabuhan pada tahun 2016 dan 97 pelabuhan pada tahun 2017. Secara umum, peningkatan jumlah pelabuhan yang paling besar ada di tahun 2016. Namun sebaliknya, jumlah pelabuhan yang tidak diusahakan menunjukkan kenaikan. Pada tahun 2012, tercatat ada sebanyak 571 pelabuhan. Kemudian mengalami peningkatan menjadi 574 pelabuhan pada 2015, jumlah tersebut dirasa masih belum berimbang untuk memenuhi kebutuhan pelayaran di Indonesia (Departemen Perhubungan Indonesia, 2017 dalam Purnamasari, 2018).

PT Pelabuhan Indonesia III (Persero) merupakan badan usaha yang sepenuhnya dimiliki oleh Pemerintah Republik Indonesia (Pemerintah) atau BUMN. PT Pelindo III, bertindak sebagai terminal operator yang mengoperasikan 43 pelabuhan dengan 16 cabang di 7 provinsi. Sebagai BUMN, selain diamanatkan untuk mengejar keuntungan, PT Pelindo III (Persero) juga diwajibkan menjadi kepanjangan tangan pemerintah dalam pemerataan kesejahteraan masyarakat dan melayani kepentingan umum.

Pendapatan PT Pelindo III pada semester I tahun 2018 tercatat sebesar Rp 4.56 triliun di mana pendapatan terbesar diperoleh dari segmen usaha petikemas sebesar Rp 2.6 triliun. Sedangkan segmen pelayanan penumpang tercatat sebesar Rp 33.7 miliar pada akhir tahun 2017, di mana penumpang non domestik sebesar Rp 3.5 miliar dan penumpang domestik sebesar $\mathrm{Rp}$ 30.1 miliar atau persentase masing-masing sebesar $11.9 \%$ dan $89.4 \%$. Apabila dibandingkan dengan barang, segmen penumpang hanya menyumbang sekitar $0.74 \%$ dari total pendapatan.

Pendapatan yang diperoleh oleh PT Pelindo III tidak lepas dari strategi yang diterapkan oleh perusahaan. Strategi khususnya pemasaran me- nurut Assauri (2008) adalah serangkaian tujuan dan sasaran, kebijakan dan aturan yang memberi arah kepada usaha-usaha pemasaran perusahaan dari waktu ke waktu, pada masing-masing tingkatan dan acuan serta alokasinya, terutama sebagai tanggapan perusahaan keadaan persaingan yang selalu berubah. Sedangkan menurut Kotler dan Amstrong (2012) logika pemasaran di mana perusahaan berharap dapat menciptakan nilai bagi customer dan dapat mencapai hubungan yang menguntungkan dengan pelanggan. Dengan demikian dapat disimpulkan bahwasanya strategi marketing merupakan suatu tindakan yang mengarah pada kegiatan atau usaha pemasaran yang bertujuan untuk menciptakan value bagi customer. Untuk menciptakan value tersebut PT Pelindo III sejauh ini telah menerapkan beberapa strategi marketing sebagai berikut.

1. Pembagian jenis kapal penumpang (penumpang domestik dan penumpang non-domestik) dengan demikian terdapat perbedaan fasilitas yang ditawarkan,

2. Perbedaan tarif penumpang, di mana penumpang non-domestik (penumpang asing) membayar dalam bentuk mata uang USD,

3. Meningkatkan kapasitas pelayanan publik pelabuhan, dilakukan dengan meningkatkan kuantitas dan kualitas pelayanan untuk terminal penumpang, di antaranya dilakukan dengan menambah/memperbesar terminal penumpang sehingga dapat menampung lebih banyak penumpang di ruang tunggu, selain itu dilakukan pengerukan terhadap kolam dan alur pelayaran sehingga kapasitas kapal penumpang yang singgah di pelabuhan juga lebih banyak. Selain itu, peningkatan standar pelayanan dengan membudayakan pelayanan prima, pengelolaan pengaduan, penilaian kepuasan pelanggan, serta pemanfaatan teknologi informasi. 
Berdasarkan hasil observasi diketahui bahwasannya saat ini PT Pelindo III sedang berencana melakukan pengembangan Pelabuhan Benoa di Bali sebagai Pelabuhan Cruise Turn Around Port. Turn around port adalah sebuah istilah di industri pelabuhan. Aliansi Otoritas Pelabuhan Amerika (APPA) mendefinisikan turn around port adalah sebuah pelabuhan yang memungkinkan untuk menaikkan dan menurunkan penumpang untuk melakukan jadwal perjalanan. Definisi lain, turn around port merupakan sebuah status bagi pelabuhan yang menjadi tempat pemberangkatan (embarkasi) dan penurunan (debarkasi) utama dan menjadi tempat dimulainya setiap perjalanan International Cruise.

Pemilihan Pelabuhan Benoa sebagai cruise turn around port yang pertama adalah karena Bali memiliki connecting flight internasional dengan rute yang lengkap dan yang kedua karena Bali memiliki objek-objek wisata dan juga fasilitas untuk menginap, dengan kata lain Bali merupakan destinasi wisata yang paling siap untuk dikunjungi turis asing dan kapal pesiar. Hal-hal tersebut sejalan dengan pendapat Managing Director Cruise Asia, Yasa Sediya yang mengatakan bahwa "Pelabuhan Benoa sudah beberapa tahun menjadi permintaan kapal pesiar tetapi cuma sampai sekarang belum terjadi. Industri mengharapkan Pelabuhan Benoa bisa menjadi turn around port. Kapal pesiar bisa mendatangkan kunjungan turis asing yang banyak" (Prodjo dan Ashdiana, 2016). Menurut BMI Research (2018), dikatakan bahwa kunjungan Cruise serta Yacht didorong oleh adanya tujuan wisata yang ada di daerah tersebut termasuk di dalamnya fasilitas yang memadai untuk sandar kapal. Medcruise (2016) mengatakan bahwa cruise merupakan salah satu industri yang terus mengalami peningkatan hingga 148\% dalam 15 tahun terakhir di mana jumlah penum- pang pada tahun 2002 tercatat sebesar 11.1 juta penumpang dan tahun 2016 sebesar 27.5 juta penumpang, dengan demikian pernyataan keduanya mendukung bahwasanya pemilihan Pelabuhan Benoa Bali sebagai Cruise Turn Around Port tepat. Selain itu, menurut hasil pengamatan PT Pelindo III pada tahun 2018 diketahui bahwa jumlah kapal yang sandar di Pelabuhan Tanjung Perak di Surabaya dengan Pelabuhan Benoa di Bali memiliki jumlah perbedaan yang cukup signifikan, di mana realisasi kapal Cruise yang sandar di Surabaya sebanyak 10 kapal, sedangkan di Bali sebanyak 56 kapal. Maka secara tidak langsung hal tersebut membenarkan bahwa tujuan wisata berpengaruh signifikan dalam menentukan jumlah kunjungan kapal.

Lebih lanjut, Kementerian Pariwisata Republik Indonesia telah memperkenalkan 10 destinasi wisata sebagai 'Bali Baru'. Destinasi prioritas tersebut yakni, Danau Toba (Sumatera Utara), Tanjung Kelayang (Bangka Belitung), Tanjung Lesung (Banten), Kepulauan Seribu (DKI Jakarta), Candi Borobudur (Jawa Tengah), Gunung Bromo \& Gunung Semeru (Jawa Timur), Labuhan Bajo (Nusa Tenggara Timur), Mandalika (Nusa Tenggara Barat), Wakatobi (Sulawesi Tenggara), dan Morotai (Maluku Utara). Delapan dari 10 destinasi wisata tersebut merupakan wisata maritim dan dapat dioptimalkan untuk menjadi wisata marina. Marina merupakan pelabuhan kecil ataupun teluk tempat bersandarnya kapal-kapal kecil dan kapal wisata (yacht) dan tidak melayani kegiatan bongkar muat barang dan penumpang dalam skala besar. Melihat peluang tersebut PT Pelindo III akan berusaha memaksimalkan rencana pengembangan Pelabuhan Benoa Bali serta mengembangkan fasilitas pelabuhan di daerah yang menjadi destinasi kapal Cruise dan Yacht, seperti di pantai Boom di Banyuwangi, Gilimas-Lembar dan La- 
buan Bajo. Pengembangan ini dilakukan untuk meningkatkan margin PT Pelindo III, hal ini sejalan dengan beberapa penelitian terdahulu yang menjelaskan bahwa mayoritas pelabuhan di dunia berusaha untuk menarik operasional home port atau turn around port cruise di pelabuhan mereka yang memberikan margin tinggi serta berdampak positif pada perekonomian lokal (Brida \& Zapata, 2010; CastilloManzano, Lopez-Valpuesta, \& Alanis, 2015).

\section{Perumusan Masalah}

Berdasarkan latar belakang dan identifikasi masalah di atas maka rumusan permasalahan penelitian ini adalah sebagai berikut. "Bagaimanakah strategi PT Pelabuhan Indonesia III (Persero) dalam pengembangan Pelabuhan Benoa sebagai Cruise Turn Around Port?"

\section{Tujuan Penelitian}

Berdasarkan perumusan masalah di atas maka tujuan penelitian ini adalah sebagai berikut.

1. Untuk mengetahui strategi PT Pelabuhan Indonesia III (Persero) dalam pengembangan Pelabuhan Benoa sebagai Cruise Turn around Port.

2. Untuk memberikan rekomendasi strategi PT Pelabuhan Indonesia III (Persero) dalam pengembangan Pelabuhan Benoa sebagai Cruise Turn around Port.

\section{Manfaat Penelitian}

Terdapat beberapa manfaat dari penelitian ini baik secara teoretis maupun manfaat secara praktis. Manfaat-manfaat tersebut adalah sebagai berikut.

1. Bagi perusahaan

Hasil dari penelitian ini diharapkan dapat memberikan kontribusi bagi PT Pelabuhan
Indonesia III (Persero) dalam menyusun strategi dan mengembangkan Pelabuhan Benoa sebagai Cruise Turn around Port.

2. Bagi pihak lainnya Penelitian ini diharapkan dapat menjadi sumber referensi bagi peneliti lainnya yang berkeinginan mengembangkan penelitian tentang strategi khususnya marketing pada perusahaan jasa.

\section{TINJAUAN PUSTAKA}

\section{Penelitian Terdahulu}

a. "Analisis SWOT dan Penyusunan Strategi Pemasaran Pelabuhan Ferry Internasional Sekupang" oleh Benny Syahroni (2012). Penelitian ini bertujuan untuk mengetahui faktor-faktor yang menjadi kekuatan dan kelemahan serta peluang dan ancaman pelabuhan ferry internasional Sekupang dan analisis posisi pelabuhan ferry internasional Sekupang dibandingkan dengan pelabuhan umum dan pelabuhan khusus lainnya, serta bagaimana proses penyusunan strategi pemasaran pada pelabuhan ferry internasional Sekupang.

b. "Pengembangan Transportasi Laut dalam Upaya Meningkatkan Konektivitas di Wilayah Nusa Tenggara Timur” oleh Syafril dan Feronika, 2017. Penelitian ini membahas rekomendasi pengembangan transportasi laut, sehingga terdapat konektivitas antar-pelabuhan yang terdapat di Provinsi NTT dan dengan pelabuhan provinsi lain.

c. "Prospect and Challenges of Cruise Tourism Development in Sri Lanka "oleh Sampath and Suranga, 2017. Tujuan penelitian ini adalah menggambarkan peluang serta tantangan pengembangan cruise tourism di Sri Lanka, serta peran serta semua pihak dalam 
menyelesaikan masalah yang timbul pasca pengembangan daerah pariwisata.

\section{Strategi Marketing}

Menurut Assauri (2008) strategi pemasaran yang dapat dijalankan oleh perusahaan dapat dibedakan ke dalam tiga jenis sebagai berikut.

a. Strategi pemasaran yang tidak membedabedakan pasar (undifferentiated marketing) Dengan strategi ini, perusahaan menganggap pasar sebagai suatu keseluruhan, sehingga perusahaan hanya memperhatikan kebutuhan konsumen secara umum, Oleh karena itu, perusahaan hanya menghasilkan dan memasarkan satu macam produk saja dan berusaha menarik semua pembeli dan calon pembeli dengan suatu rencana pemasaran saja. Strategi ini bertujuan untuk melakukan penjualan secara massal, sehingga menekan biaya. Perusahaan memusatkan perhatiannya pada seluruh konsumen dan kebutuhannya, serta merancang produk yang dapat menarik sebanyak mungkin para konsumen tersebut.

b. Strategi pemasaran yang membeda-bedakan pasar (differentiated marketing)

Dengan strategi ini, perusahaan hanya melayani kebutuhan beberapa kelompok konsumen tertentu dengan jenis produk tertentu pula. Jadi perusahaan atau produsen menghasilkan dan memasarkan produk yang berbeda-beda untuk tiap segmen pasar. Perusahaan yang menggunakan strategi ini bertujuan untuk mempertebal kepercayaan kelompok konsumen tertentu terhadap produk yang dihasilkan dan dipasarkan sehingga pembeliannya akan dilakukan berulang kali.

c. Strategi pemasaran yang terkonsentrasi (concentrated marketing)

Dengan strategi ini, perusahaan mengkhususkan pemasaran produknya dalam beberapa segmen pasar, dengan pertimbangan keterbatasan sumber daya perusahaan. Strategi pemasaran ini mengutamakan seluruh usaha pemasaran pada satu atau beberapa segmen pasar tertentu saja. Jadi perusahaan yang memusatkan segala kegiatan akan memberikan keuntungan yang terbesar.

\section{Segmentation}

Segmentasi adalah membagi sebuah pasar menjadi kelompok -kelompok pembeli dengan keinginan, karakteristik, atau perilaku yang berbeda-beda (Kotler \& Amstrong, 2008 dalam Tania dan Dharmayanti, 2014). Menurut Tjiptono dan Chandra (2012) dalam Hanafrian (2017) bahwa pengertian segmentasi pasar adalah sebagai proses mengelompokkan pasar keseluruhan yang heterogen menjadi kelompokkelompok atau segmen-segmen yang memiliki kesamaan dalam hal kebutuhan, keinginan, perilaku dan atau respons terhadap program pemasaran spesifik.

\section{Targeting}

Targeting merupakan proses mengevaluasi dan memilih satu atau beberapa segmen pasar yang dinilai paling menarik untuk dilayani dengan program pemasaran spesifik perusahaan (Tjiptono dan Chandra, 2012 dalam Tania dan Dhamrayanati, 2014). Menurut Keegan dan Green, targeting adalah proses pengevaluasian segmentasi dan pemfokusan strategi pemasaran kepada sebuah negara, provinsi, atau sekelompok orang yang memiliki potensi untuk memberikan respons. Target pasar juga diartikan sebagai kegiatan yang berisi dan menilai serta memilih satu atau lebih segmen pasar yang akan dimasuki oleh suatu perusahaan (Wijaya dan Sirine, 2017 dalam Takdir, 2017). 


\section{Positioning}

Definisi positioning menurut Kotler dan Keller (2009) adalah suatu aktivitas perusahaan dalam memberikan suatu citra yang ditaruh di dalam benak pikiran pasar sasaran atau target konsumen. Dari definisi ini dijelaskan bahwa positioning memiliki tujuan untuk melokasikan suatu brand di dalam pikiran konsumen agar dapat memberikan nilai tambah (manfaat) yang lebih kepada perusahaan.

\section{Cruise Turn around Port}

Turn around Port merupakan istilah di dunia kepelabuhanan di mana Siriwardena dan Silva (2017) mendeskripsikan turn around port sebagai pelabuhan bagi kapal cruise dalam menaikkan dan menurunkan penumpang. Lebih lanjut, disebutkan pula bahwa pelabuhan ini bukanlah pelabuhan tujuan utama bagi para penumpang akan tetapi memiliki kapabilitas dan kapasitas dalam melayani perjalanan kapal cruise. Adapun, turn around port hanya dapat dimungkinkan apabila pada daerah pelabuhan dimaksud memiliki jumlah international connecting flight yang cukup serta aksesibilitas ke terminal penumpang di area pelabuhan.

Hal senada dari Cruise Line International Association (2017) juga menjelaskan lebih lanjut bahwa pada turn around port, kapal-kapal cruise tidak hanya melakukan aktivitas sandar serta menaikkan dan menurunkan penumpang, namun juga melakukan aktivitas pengisian perbekalan seperti bahan bakar, air bersih, logistik, makanan, dan lain sebagainya.

Lebih lanjut, menurut internal PT Pelindo III turn around port memiliki potensi untuk mendongkrak aktivitas ekonomi di lingkungan sekitar pelabuhan atau dengan kata lain memiliki domino effect. Beberapa industri yang dipengaruhi langsung adalah penginapan, pusat perbelan- jaan dan restoran atau tempat makan. Adapun, terdapat kesempatan bagi perencana perjalanan untuk menjadwalkan waktu wisata pada tujuan wisata pelabuhan dimaksud.

\section{Porter's Analysis Framework}

Dalam perkembangan ilmu manajemen, konsep mengenai strategi terus berubah. Para pemikir dan konsultan manajemen memberikan berpuluh model dan kerangka berpikir (framework) untuk menganalisis pilihan strategi (Hambrick dan Fredrickson, 2005).

Strategi merupakan alat untuk mencapai tujuan perusahaan dalam kaitannya dengan tujuan Strategi merupakan alat untuk mencapai tujuan perusahaan dalam kaitannya dengan tujuan jangka panjang, program tindak lanjut, serta prioritas alokasi sumber daya. Strategi merupakan respons secara terus menerus maupun adaptif, terhadap peluang dan ancaman eksternal serta kekuatan dan kelemahan internal yang dapat memengaruhi organisasi. Hambrick dan Fredrickson (2005) menekankan bahwa para Chief Executing Officer (CEO), kepala divisi, atau siapa pun entrepreneur, harus mempunyai strategi untuk bisa mencapai tujuan organisasi.

1. The Threat of New Entrants (masuknya pesaing baru)

2. The Power of Suppliers (kekuatan penawaran pemasok)

3. The Power of Buyers (kekuatan penawaran pembali)

4. The Threat of Substitutes (ancaman dari produk pengganti/substitusi)

5. Rivalry among Existing Competitors (persaingan di antara pesaing yang ada)

Kelima kekuatan tersebut menentukan profitabilitas industri karena memengaruhi harga, biaya, dan memerlukan investasi perusahaan di 
dalam suatu industri. Profitabilitas industri tidak bergantung pada bagaimana tampaknya produksi bersangkutan atau apakah fungsi itu mencakup teknologi tinggi atau rendah, tetapi tergantung pada struktur industri. Kekuatan masing-masing dari kelima kekuatan bersaing merupakan fungsi struktur industri, atau karakteristik ekonomi dan teknis yang mendasari suatu industri. Dengan mempelajari kelima hal ini, manajer dapat memformulasikan strategi yang akan menjadikan perusahaan lebih profit dan menjadi kurang vulnerable menghadapi pasar (Porter, 2008).

\section{METODE PENELITIAN}

\section{Pendekatan Penelitian}

Pendekatan penelitian yang digunakan dalam penelitian ini adalah penelitian kualitatif. Pendekatan kualitatif diartikan sebagai sebuah proses penyelidikan bertujuan memahami masalah baik itu manusia atau sosial, berdasarkan pada penciptaan gambaran holistis lengkap yang dibentuk melalui kata-kata dalam bentuk laporan pandangan pemberi informasi secara rinci dan disusun dalam sebuah latar alamiah (Cresswell, 2002). Penelitian deskriptif kualitatif yang digunakan pada penelitian ini dilakukan dengan studi mendalam serta mempertimbangkan kedalaman data dengan pertimbangan kemudahan untuk mendalami, menggali informasi lebih banyak dan akurat.

\section{Jenis dan Sumber Data}

Jenis dan sumber data yang digunakan dalam penelitian ini adalah data primer dan data sekunder (Marzuki, 2002). Sumber data berasal dari hasil wawancara dengan key informants serta hasil pengamatan atas fenomena di lapangan pada objek penelitian. Data sekunder, meng- acu pada informasi yang dikumpulkan dari sumber yang telah ada. Data sekunder dapat berupa laporan, buku-buku, pedoman, dan peraturan pelaksanaan.

\section{Teknik Pengumpulan Data}

Pengumpulan data pada penelitian ini dilakukan dengan cara membagi menjadi tiga tahap. Pertama, survei pendahuluan untuk memperoleh gambaran perusahaan dalam hal ini PT Pelindo III secara umum, dan mempelajari strategi marketing PT Pelindo III secara khusus. Kedua, pengorganisasian penelitian yang terdiri dari tahap persiapan, pencarian jurnal dan teoriteori yang terkait. Ketiga, pengumpulan data melalui wawancara dan pengumpulan dokumen perusahaan terkait.

\section{Key Informants}

Pada penelitian ini, akan dilakukan interview dengan beberapa key informants berdasarkan struktural organisasi PT Pelabuhan Indonesia III (Persero), yaitu Direktur Operasi dan Komersial, Senior Vice President Marketing, Senior Vice President Corporate Strategic Planning and Performance dan Vice President Tourism. Kemudian, key informan eksternal PT Pelabuhan Indonesia III (Persero) adalah customer yakni General Manager PT Equator Marindo dan Manager Operation PT Beahari Eka Nusantara.

\section{Teknik Analisis Data}

Analisis data menggunakan metode kualitatif deskriptif. Perolehan data melalui wawancara dalam penelitian ini di analisis menggunakan analisis deskriptif kualitatif yaitu pendeskritifikan data hasil wawancara dari key informants secara 
menyeluruh di mana data wawancara dalam penelitian ini adalah sumber data utama yang menjadi bahan analisis data untuk menjawab masalah penelitian. Proses analisis data dimulai dengan membuat transkrip hasil wawancara lebih dahulu, hal yang dilakukan terkait transkrip hasil wawancara adalah dengan cara memutar kembali rekaman wawancara kemudian menuliskan kata-kata yang sesuai dengan apa yang ada di rekaman tersebut. Kemudian, setelah penulisan transkrip selesai selanjutnya peneliti membuat reduksi data dengan cara abstraksi, yaitu dengan mengambil data yang sesuai dengan konteks penelitian dan mengabaikan data yang tidak diperlukan. Triangulasi digunakan sebagai penguji keabsahan data di mana data di luar penelitian digunakan untuk pengecekan atau sebagai pembanding. Keabsahan data dilakukan dengan maksud agar data yang dihasilkan dapat dipercaya dan dipertanggungjawabkan secara ilmiah.

\section{ANALISIS DAN PEMBAHASAN}

\section{Segmentation, Targeting dan Positioning PT Pelin-} do III (Persero)

\section{Segmentation}

Berdasarkan penelitian Kotler, Bowen dan Makens (2012) diketahui PT Pelabuhan Indonesia III (Persero) menetapkan segmentasi atas dasar geografis. Sesuai dengan dokumen internal perusahaan (Dokumen KPKU, 2017) PT Pelabuhan Indonesia III (Persero) membagi segmen pelanggan menjadi dua, yakni domestik dan internasional. Adapun pada kedua segmen ini, PT Pelabuhan Indonesia III (Persero) membagi pasar-pasar yang dilayani menjadi lima jenis yakni petikemas, curah kering, curah cair, bag cargo dan other cargo. Khusus pada penelitian ini, kapal cruise masuk ke dalam jenis other cargo. Adapun PT Pelabuhan Indonesia III (Per- sero) dalam mempermudah kegiatan usahanya membagi wilayah kerja menjadi empat region sebagaimana di bawah yakni: Region Jawa Timur, Region Jawa Tengah, Region Kalimantan, dan Region Bali Nusra. Khusus untuk region Bali Nusra akan mendapat perhatian khusus dalam pembahasan penelitian ini karena pada region inilah Pelabuhan Benoa berdiri. Secara umum, region Bali Nusra memiliki arus penumpang internasional paling tinggi di antara region lain yang bersumber dari kunjungan kapal cruise dengan jumlah penumpang pada tahun 2017 sebanyak 165.492 dan pada tahun 2018 jumlah penumpang tercatat 252.305 atau meningkat $52 \%$.

\section{Targeting}

Berdasarkan penetapan segmentasi di atas maka PT Pelabuhan Indondesia III (Persero) menetapkan sasaran target usaha tidak hanya terfokus pada kondisi internal saja melainkan kondisi eksternal yang mana dalam hal ini adanya kebijakan pemerintah menjadi pertimbangan perusahaan dalam menentukan target pasar. Jika berdasarkan teori strategi, maka PT Pelabuhan Indonesia III (Persero) menetapkan target sasaran dengan Full Market Converage, di mana perusahaan berusaha untuk mencakup keseluruhan pasar yang ada dengan memenuhi kebutuhan konsumen dengan produk yang berbeda di setiap segmen pada keseluruhan pasar. Dalam hal ini, PT Pelabuhan Indonesia III (Persero) tidak hanya membatasi pada satu bisnis saja namun beberapa peluang bisnis dengan memaksimal kemampuan perusahaan. Hal ini sesuai dengan strategi bisnis perusahaan mengenai diferensiasi produk dan inovatif proaktif. Jika berdasarkan penelitian Widjaya (2017), maka strategi target pasar PT Pelabuhan Indonesia III (Persero) adalah Differentiated Marketing, di mana strategi ini diguna- 
kan perusahaan untuk menargetkan beberapa segmen pasar dan mendesain tawaran yang terpisah kepada setiap segmen pasar. Dengan menawarkan berbagai variasi produk dan pemasaran ke dalam segmen, perusahaan berharap untuk penjualan yang lebih tinggi dan posisi yang lebih kuat dalam setiap segmen pasar.

\section{Positioning}

PT Pelabuhan Indonesia III (Persero) memosisikan diri tidak hanya sebagai sebuah perusahaan yang mengejar keuntungan, namun juga sebagai agen pemerintah dalam pemerataan kesejahteraan di seluruh wilayah kerjanya. Hal ini membuat PT Pelabuhan Indonesia III (Persero) tidak leluasa melakukan gerakan bisnis dengan cepat pada umumnya. Positioning dalam hal ini menjadi kekuatan perusahaan di mana PT Pelabuhan Indonesia III (Persero) mendapatkan perlakuan dan perlindungan khusus dari pemerintah dalam bentuk regulasi yang berdasarkan undangundang maupun peraturan setingkat Kementerian.

\section{Porter's Five Forces Porter Analysis PT Pelabuhan Indonesia III (Persero)}

\section{Threat of New Entrants}

Munculnya pendatang baru (pelabuhanpelabuhan baru) yang dikelola baik oleh pemerintah (BUMN), perusahaan lokal (swasta) baik dengan bekerja sama atau tidak bekerja sama dengan investor asing tidaklah mudah, hal ini terkait dengan regulasi pemerintah serta investasi pembangunan yang cukup besar. Namun, adanya pendatang baru dan peluang akan dibukanya investor asing untuk mengelola secara langsung akan menjadikan ancaman bagi perusahaan dalam hal ini PT Pelabuhan Indonesia III (Persero). Berdasarkan data Badan Pusat Statistik tahun
2018, jumlah pelabuhan strategis di Indonesia pada tahun 2015 adalah 1.351 pelabuhan cenderung mengalami penurunan dibandingkan pada tahun 2013 dan tahun 2014. Sedangkan jumlah pelabuhan strategis berdasarkan pengelolaan pada tahun 2014 dan tahun 2015 untuk PT Pelindo cenderung tetap yaitu sebanyak 111 pelabuhan, Terminal Khusus berjumlah 480 pelabuhan, TUKS berjumlah 574 pelabuhan, sedangkan UPT mengalami penurunan semula 574 pelabuhan menjadi 186 pelabuhan pada tahun 2015.

\section{Bargaining Power of Suppliers}

Pada industri transportasi laut dalam hal ini sarana dan prasarana pelabuhan yang menjadi pemasok ataupun supplier adalah perusahaanperusahaan yang menawarkan alat berat seperti crane untuk membantu mengembangkan usaha bongkar muat pelabuhan, penyediaan sumber air bersih dengan SWRO (desalinasi air laut) atau BWRO (desalinasi air payau). Namun berdasarkan data wawancara diketahui bahwasanya pemasok kegiatan operasional adalah beberapa anak perusahaan PT Pelabuhan Indonesia yang dikondisikan sebagai supplier, di dalam wawancara tersebut disebutkan bahwa PT PEL membantu dalam memfasilitasi pengaturan gas, PPI (Pelindo Properti Indonesia) untuk mengatasi permasalahan marina (pelabuhan khusus), PT PMS (Pelindo Marinie Service) untuk memfasilitasi masalah BBM dan air.

\section{Bargaining Power of Buyers}

Pelanggan yang dimaksud di sini adalah perusahaan atau pelanggan yang membutuhkan layanan jasa angkutan transportasi laut. Para pelanggan biasanya akan menuntut suatu jasa yang berkualitas prima, layanan yang baik serta 
kemudahan dalam bertransaksi namun dengan harga yang murah. Menurut hasil wawancara, ditemukan bahwa pelanggan PT Pelabuhan Indonesia III (Persero) di antaranya adalah agen kapal dan perusahaan pelayaran (bongkar muat petikemas, kargo, bulk, kontainer). Kemudian bargaining power of buyers cukup kuat mengingat PT Pelindo III (Persero) merupakan perusahaan yang bergerak di bidang jasa. Adapun, pelanggan PT Pelindo III (Persero) pada segmen cruise berdampak langsung pada pendapatan Negara. Selain itu, kekhawatiran adanya dampak negatif word of mouth turut berpengaruh pada kunjungan ke Pelabuhan Benoa.

\section{Threat of Substitute Products or Services}

Produk/servis substitusi (pengganti) jasa transportasi laut dalam hal ini pelabuhan adalah jasa transportasi udara dan jasa transportasi darat. Pada setiap tahunnya penggunaan transportasi baik darat, udara dan laut mengalami peningkatan. Terjadi peningkatan jumlah pengguna transportasi darat (kereta api), di mana pada setiap tahunnya jumlah angkutan penumpang Pulau Jawa mengalami pertumbuhan sebesar 16,19\% sedangkan di Pulau Sumatra sebesar 14,60\%. Namun hasil ini berbanding terbalik dengan jumlah angkutan barang dengan menggunakan jasa transportasi kereta api, Pulau Sumatra mengalami peningkatan sebesar 13,78\% setiap tahunnya sedangkan Pulau Jawa sebesar 10,64\% setiap tahunnya. Transportasi laut sejauh ini lebih banyak dalam hal angkutan penumpang, berdasarkan data BPS tahun 2017 diketahui jumlah angkutan penumpang udara sebanyak hampir delapan juta orang, sedangkan bongkar muat barang jauh lebih banyak lagi dibandingkan transportasi udara. Berdasarkan data di atas maka dapat disimpulkan bahwa ada produk pengganti memberikan pilihan bagi pelanggan untuk memilih jasa transportasi berdasarkan kebutuhan.

\section{Rivalry among Existing Competitors}

Berdasarkan hasil wawancara, diketahui bahwa saat ini jasa transportasi laut dengan pengembangan usaha pelabuhan masih banyak dikelola oleh pemerintah. PT Pelabuhan Indonesia, masih mendominasi dibandingkan perusahaan lokal swasta dan asing. Akan tetapi, masih terdapat kemungkinan bagi perusahaan swasta tersebut untuk terus bersaing dengan menggandeng perusahaan lokal apabila PT Pelindo III (Persero) tidak melakukan pembenahan dari sisi pelayanan.

\section{Strategi PT Pelindo III (Persero)}

Berdasarkan hasil wawancara mengenai strategi PT Pelabuhan III (Persero), penetapan strategi perusahaan didasarkan pada visi dan misi perusahaan, di mana dahulu strategi perusahaan masuk dalam RJPP sehingga tidak menggambarkan dengan jelas strategi yang dimaksud, namun kemudian diturunkan dalam rencana kerja manajemen jangka panjang serta rencana kerja jangka pendek sehingga memudahkan setiap insani PT Pelabuhan Indonesia III (Persero) menangkap tujuan perusahaan. Gambaran strategi PT Pelindo III (Persero) dapat dikatakan belum memaksimalkan fungsi pelabuhan secara baik. Masih ada pelayanan yang belum berjalan sebagaimana seharusnya, kemudian belum adanya evaluasi lebih lanjut perihal implementasi strategi marketing yang sedang berjalan, perlunya melibatkan semua cabang dalam membuat keputusan sehingga tidak hanya pusat saja yang memiliki kewenangan untuk menentukan rencana kerja terkait dalam menunjang tercapainya tujuan 
perusahaan. Selain itu, beberapa pelaksana belum bekerja dengan baik.

Berikut ini usulan perbaikan strategi PT Pelindo III (Persero) berdasarkan penelitian.

1. Memperbaiki budaya kerja dengan pola lama, di mana kesan 'birokrat" pada perusahaan milik pemerintah masih melekat.

2. Restrukturisasi dan regenerasi sumber daya manusia, kemudian menyiapkan sumber daya manusia agar sigap dengan perubahan yang terjadi.

3. Menjaga kerjasama dan bersinergi dengan perusahaan BUMN dan mitra kerja perusahaan.

4. Pelayanan PT Pelabuhan Indonesia III (Persero) yang diberikan kepada pelanggan. Pelayanan yang dimaksudkan dapat berupa kepastian dan ketepatan waktu pelayanan.

5. Memaksimalkan fasilitas, dan dilakukan penambahan apabila diperlukan dalam rangka menunjang peningkatan pelayanan.

6. Investasi teknologi system dengan konsep Home Terminal Service. Home Terminal Service merupakan bentuk aplikasi seperti gojek yang dapat memudahkan pelanggan tanpa harus datang secara langsung.

7. Menetapkan tarif yang reasonable.

Adapun atas kondisi existing tersebut, strategi PT Pelindo III (Persero) masih belum teruji dengan baik di mana kompetitor belum banyak sehingga perlu dilakukan evaluasi dan pengembangan untuk memanfaatkan kondisi status quo. Lebih lanjut, hal yang dapat dilakukan adalah dengan mengevaluasi kembali segmentasi, target, dan positioning perusahaan sebelum menentukan pengembangan strategi baru dalam hal ini adalah rencana pengembangan strategi cruise turn around port.
Lebih lanjut, rencana pengembangan Cruise Turn Around Port di Benoa menjadi alternatif pilihan pengembangan strategi yang menjanjikan hanya saja perlu dipersiapkan dengan baik mengingat strategi PT Pelabuhan Indonesia III (Persero) secara umum dapat dikatakan belum maksimal. Selain Benoa Bali, Indonesia bagian Timur seperti Sumbawa dan Raja Ampat dapat menjadi pertimbangan lain.

\section{Keterbatasan Penelitian}

Keterbatasan dalam penelitian ini antara lain adalah objek penelitian hanya meneliti rencana Pelabuhan Benoa menjadi turn around port sebagai objek penelitian, tidak meneliti alternatif pengembangan lainnya. Di samping itu, proporsi key informant pada penelitian ini lebih banyak dari sisi PT Pelabuhan Indonesia III (Persero) atau dapat dikatakan internal's key informant dalam penelitian ini lebih dominan.

Selain itu, penelitian ini tidak menganalisis dampak biaya dan beban finansial atas strategi yang dilakukan oleh perusahaan. Titik berat dari penelitian ini lebih pada peningkatan pendapatan dan pasar perusahaan yang berkaitan dengan cruise turn around port Pelabuhan Benoa.

Hal lain yang dapat dilakukan di antaranya dapat meneliti atau mengevaluasi kembali implementasi pengembangan strategi turn around port pada PT Pelabuhan Indonesia III (Persero) dengan menambahkan key informants eksternal perusahaan sehingga akan mendapatkan informasi serta perspektif yang lebih luas, kemudian mengevaluasi strategi bauran pemasaran PT Pelabuhan Indonesia III (Persero) dan re-evaluasi penetapan Segmentasi, Targeting, dan Positioning (STP) Strategi Pemasaran PT Pelabuhan Indonesia III (Persero). 


\section{KESIMPULAN DAN SARAN}

Kesimpulan

Berdasarkan hasil penelitian mengenai" Strategi PT Pelabuhan Indonesia III (Persero) dalam pengembangan Pelabuhan Benoa sebagai Cruise Turn around Port" maka dapat diambil kesimpulan sebagai berikut.

1. Bagaimanakah strategi PT Pelabuhan Indonesia III (Persero) dalam pengembangan Pelabuhan Benoa sebagai Cruise Turn around Port?

Strategi yang diterapkan oleh PT Pelabuhan Indonesia III (Persero) dapat dikatakan belum memaksimalkan fungsi pelabuhan secara baik. Hal ini terkait dengan adanya pelayanan yang masih belum berjalan sebagaimana seharusnya, kemudian belum adanya evaluasi lebih lanjut perihal implementasi strategi khususnya dalam konteks marketing yang sedang berjalan, perlunya melibatkan semua cabang dalam membuat keputusan sehingga tidak hanya pusat saja yang memiliki kewenangan untuk menentukan rencana kerja terkait dalam menunjang tercapainya tujuan perusahaan. Selain itu, peran sumber daya manusia sebagai pelaksana belum bekerja dengan baik. Namun, rencana pengembangan Cruise Turn around Port di Benoa menjadi alternatif pilihan pengembangan strategi yang menjanjikan hanya saja perlu dipersiapkan dengan baik mengingat strategi yang dilakukan PT Pelabuhan Indonesia III (Persero) dapat dikatakan belum maksimal.

2. Rekomendasi strategi PT Pelabuhan Indonesia III (Persero) dalam pengembangan Pelabuhan Benoa sebagai Cruise Turn Around Port?

Pada dasarnya sebelum menentukan ataupun memutuskan pengembangan strategi, alangkah lebih baik jika PT Pelabuhan Indonesia
III (Persero) melakukan evaluasi. Kemudian beberapa hal yang dapat dilakukan adalah sebagai berikut.

a. Memperbaiki budaya kerja dengan pola lama, di mana kesan 'birokrat" pada perusahaan milik pemerintah masih melekat.

b. Restrukturisasi dan regenerasi sumber daya manusia, kemudian menyiapkan sumber daya manusia agar sigap dengan perubahan yang terjadi.

c. Menjaga kerjasama dan bersinergi dengan perusahaan BUMN dan mitra kerja perusahaan.

d. Pelayanan PT Pelabuhan Indonesia III (Persero) yang diberikan kepada pelanggan. Pelayanan yang dimaksudkan dapat berupa kepastian dan ketepatan waktu pelayanan.

e. Memaksimalkan fasilitas dan menambahkan jika diperlukan dalam menunjang peningkatan pelayanan.

f. Menetapkan tarif yang reasonable.

Saran

Dari hasil penelitian ini dapat dikemukakan beberapa saran yang dapat dipertimbangkan atau dimanfaatkan sebagai bahan dalam pengambilan keputusan, antara lain sebagai berikut.

Pelabuhan Benoa telah memiliki keunggulan eksternal strategis dalam upayanya untuk menjadi cruise turn around port yakni lokasi Pulau Bali yang telah memiliki tujuan wisata bagi wisatawan asing dan domestik serta connecting flight yang lengkap juga aksesibilitas yang menjangkau hingga ke area pelabuhan. Untuk itu, PT Pelindo III (Persero) perlu melakukan perbaikan internal sebagaimana tercantum pada kesimpulan agar mendukung dan memperkuat keunggulan eksternal dimaksud. 


\section{DAFTAR PUSTAKA}

Assauri, Sofyan, 2008. Manajemen Pemasaran: Dasar, Konsep, dan Strategi, Cetakan Kedelapan. Jakarta: PT Raja Grafindo.

BPS. 2017. Transportasi Darat 2017, diunduh melalui https://www.bps.go.id/

BPS. 2017. Transportasi Laut 2017, diunduh melalui https://www.bps.go.id/

BPS. 2017. Transportasi Udara 2017, diunduh melalui https://www.bps.go.id/

BPS. 2018. Data Statistik Pelabuhan Strategis di Indonesia, diunduh melalui https://www. bps.go.id/

Brida \& Zapata. 2011. Residents' Attitudes and Perceptions towards Cruise Tourism Development: A Case Study of Cartage de India's (Colombia). Tourism and Hospitality Research, Vol.1, No. 3, Hal: 187-202.

Castillo-Manzano, Lopez-Valpuesta, \& Alanis. 2014. Tourism Managers' View of the Economic Impact of Cruise Traffic: The Case of Southern Spain. Current Issues in Tourism, Vol. 18, No.7, Hal: 701-705.

Chiappa, Lorenzo - Romero, Galarza. 2018. Host Community Perceptions of Cruise Tourism in a Homeport: A Cluster Analysis. Journal of Destination Marketing \& Management, Vol. 7, Hal: 170-181.

Company Profile PT Pelindo III. 2018.

Creswell, John W. 2002. Desain Penelitian. Jakarta: KIK Press.

Cruise Line International Association. 2017, diunduh melalui https://cruising.org/

Daft, Richard L. 2010. Understanding the Theory and Design of Organizations 10th Edition. Asia - China: South Western, Cengage Learning.

Dolan, R.J. 1991. Strategic Marketing Management. Boston: Business School Publication
Gusnur. 2008. Tantangan Pemasaran Abad 21, diunduh melalui http://gusnur69.wordpress.com.

Hambrick and Fredrickson. 2005. Are You Sure You Have A Strategy. Academy of Management Executive, Vol.19, No.4.

Hanafrian, Ruri Hafizh. 2017. Tinjauan Strategi Segmentasi, Targeting, Positioning (Stp) Pada PT Soka Cipta Niaga. Jurnal e-Proceeding of Applied Science, Vol.3, No.2, Hal: 338-344.

Koentjaraningrat. 1993. Metode-Metode Penelitian Masyarakat. Jakarta: PT Gramedia Pustaka Utama.

Kotler, Philip dan Amstrong, Gary. 2009. PrinsipPrinsip Pemasaran, Edisi 12, Jilid 2. Jakarta: Erlangga.

Kotler, Philip dan Amstrong, Gary. 2012. PrinsipPrinsip Pemasaran, Edisi 13 Jilid 1. Jakarta: Erlangga.

Kotler, Philip dan Armstrong, Gary. 2008. Manajemen Pemasaran, Jilid 1, Alih Bahasa oleh Benyamin Molan, Edisi 12. Jakarta: PT Indeks.

Kotler, Philip dan Keller, Kevin Lane. 2009. Manajemen Pemasaran, Edisi 13, Jilid 1. Jakarta: Erlangga.

Kotler, Philip dan Keller, Kevin Lane. 2012. Marketing Management 13th. New Jersey: Pearson Prentice Hall, Inc.

Laporan Tahunan. 2017. Laporan Tahunan PT Pelabuhan Indonesia III (Persero), diunduh melalui https://www.pelindo.co.id/info-investor/laporan/q/annual-report.

Lubis, Arlina Nubaity. 2004. Strategi Pemasaran dalam Persaingan Bisnis. USU Digital Library. Program Studi Ilmu Manajemen Fakultas Ekonomi Universitas Sumatera Utara. 
Marzuki. 2002. Metodologi Riset. Yogyakarta: Fakultas Ekonomi Universitas Islam Indonesia.

Moleong, Lexy J. 2012. Metodologi Penelitian Kualitatif. Bandung: PT Remaja Rosdakarya.

Nugroho et al. 2017. Strategi Pengembangan Bisnis PT Pelayaran Bahtera Adhiguna dalam Industri Pelayaran. ALBACORE, Vol. 1, No. 3, Hal: 321-336.

Palmer, Adrian. 2001. Principles of Service Marketing 13th Edition. United Stated of America: McGraw Hill.

Porter, Michael E. 2008. Strategy Bersaing (Competitive Strategy). Tangerang: Kharisma Publishing Group.

Purnamasari, Desi. 2018. Sejauh Mana Perbaikan Infrastruktur Laut Indonesia? diunduh melalui https://tirto.id/sejauh-mana-perbaikaninfrastruktur-laut-indonesia-cMJG.

Purnomo, Cahya. 2010. Pentingnya Pemasaran Jasa Angkutan Laut di Indonesia. BAHARI Jogia, Vol.X, No.17.

Rangkuti, F. 2004. Strategi Promosi Yang Kreatif: Analisis Kasus Integrated Marketing Communication. Jakarta: Gramedia Pustaka Utama.

Siriwardena, Sampath and Suranga, DAC Silva. 2017. Prospect and Challenges of Cruise Tourism Development in SriLanka. SEUSL Journal of Marketing, Vol. 2. No. 1. Hal: $1-25$.
Sugiyono. 2002. Metode Penelitian Administrasi. Bandung: CV Alfabeta.

Susanto dan Wijanarko. 2004. Power Branding: Membangun Merek Unggul dan Organisasi Pendukungnya. Jakarta: Mizan Publika Jakarta.

Suyanto. 2007. Marketing Strategi Top Brand Indonesia. Yogyakarta: CV Andi Offset.

Syafril dan Feronika. 2017. Pengembangan Transportasi Laut dalam Upaya Meningkatkan Konektivitas di Wilayah Nusa Tenggara Timur. Warta Penelitian Perhubungan, Vol. 29, No. 2, Hal: 241-252.

Syahroni, Benny. 2012. Analisis SWOT dan Penyusunan Strategi Pemasaran Pelabuhan Ferry Internasional Sekupang. Program Pascasarjana Universitas Terbuka Jakarta. Takdir. 2017. Pengaruh Strategi STP dan Personal Selling Terhadap Peningkatan Penjualan pada PT Bumi Sarana Utama di Makassar. Fakultas Ekonomi dan Bisnis Islam Universitas Islam Negeri Alauddin.

Tania, Debby dan Dharmayanti, Diah. 2014. Market Segmentation, Targeting, dan Brand Positioning dari Winston Premier Surabaya. Jurnal Manajemen Pemasaran Petra, Vol.2, No.1, Hal: 1-7

Tjiptono, Fandy. 2006. Strategi Pemasaran. Yogyakarta: CV Andi Offset.

Widjaya, Pieter Gunawan. 2017. Analisis Segmenting, Targeting, Positioning, dan Marketing Mix pada PT Murni Jaya. Jurnal AGORA, Vol. 5, No. 1. 